\title{
$P$ wave dispersion and cardiac involvement in patients with juvenile idiopathic arthritis
}

\author{
Bulent Koca, Ozgur Kasapcopur, Suleyman Bakari, Emre Celik, Ayse Guler Eroglu, Levent Saltik, Funda Oztunc, \\ Ozden Calay
}

From 18th Pediatric Rheumatology European Society (PReS) Congress

Bruges, Belgium. 14-18 September 2011

\section{Background and aim}

Juvenile idiopathic arthritis (JIA) is the most common rheumatologic disorder of childhood. Cardiac involvement as pericarditis, myocarditis and valvular disease is common in JIA (JIA). There are, however, few descriptions concerning systolic and diastolic functions of the left ventricle (LV) in children with JIA. P wave dispersion (PWD) is a sign for the prediction of atrial fibrillation (AF). A recent study found that rheumatoid arthritis patients had an abnormally high $P$ wave duration and PWD , markers for supraventricular arrhythmogenicity. The study was to assess PWD and its relation with systolic and diastolic function of the LV in a group of children with JIA.

\section{Methods}

We performed electrocardiography and Doppler echocardiography on 50 patients with JIA and 70 healthy controls. Maximum and minimum $\mathrm{P}$ wave duration were obtained from electrocardiographic measurements. PWD defined as the difference between maximum and minimum $\mathrm{P}$ wave duration was also calculated.

\section{Results}

No statistically significant differences were found between the groups in minimal, maximal $\mathrm{P}$ wave duration and PWD (Table 1). Among the diastolic

Table 1 Electrocardiographic measurements of the JIA patients and controls

\begin{tabular}{llll}
\hline & JIA & $\begin{array}{l}\text { Controls } \\
\text { (mean } \pm \text { SD) }\end{array}$ & P value \\
\hline Maximum P wave duration (ms) & $79.62 \pm 11$ & $81.31 \pm 9.11$ & NS \\
Minimum P wave duration (ms) & $55.20 \pm 11.12$ & $56.63 \pm 10.41$ & NS \\
P wave dispersion (ms) & $24.42 \pm 11.40$ & $25.62 \pm 10.24$ & NS \\
\hline
\end{tabular}

parameters, increased late flow velocity, decreased early flow velocity and prolonged isovolumic relaxation time reflected an abnormal relaxation form of diastolic dysfunction. During 12 months of follow-up, no supraventricular arrhythmias were documented in either group.

\section{Conclusions}

$\mathrm{P}$ wave duration and PWD was not found to be higher in JIA patients than healthy control subjects. Larger observational studies and prolonged follow-up are therefore required before definitive conclusions can be made.

Published: 14 September 2011

doi:10.1186/1546-0096-9-S1-P142

Cite this article as: Koca et al:: $\mathrm{P}$ wave dispersion and cardiac

involvement in patients with juvenile idiopathic arthritis. Pediatric Rheumatology 2011 9(Suppl 1):P142.
Submit your next manuscript to BioMed Central and take full advantage of:

- Convenient online submission

- Thorough peer review

- No space constraints or color figure charges

- Immediate publication on acceptance

- Inclusion in PubMed, CAS, Scopus and Google Scholar

- Research which is freely available for redistribution
C Biomed Central 